\title{
OTIOTOMICS
}

Revista de economía, empresa y sociedad

Dossier «Economía social y solidaria: experiencias y retos»

ALTERNATIVAS

\section{La economía del futuro debe ser social y solidaria}

\section{Jordi Garcia Jané}

Socio de la cooperativa L'Apòstrof

RESUMEN Desde la década de 1980 proliferan alrededor del mundo las iniciativas socioeconómicas regidas por lógicas distintas a la acumulación, el máximo beneficio y el consumismo, propias de la economía capitalista. Estas nuevas iniciativas aparecen en todo el ciclo económico: la gestión de los recursos, la producción, la comercialización, el consumo, el sistema financiero, la distribución del excedente y la circulación monetaria. Una de las formas más extendidas para denominarlas es economía social y solidaria, y en el futuro pueden devenir una alternativa a la economía dominante.

PALABRAS CLAVE economía social y solidaria; cooperativismo; comunes; trabajo cooperativo; comercialización justa; consumo responsable; finanzas éticas; monedas comunitarias; distribución solidaria del excedente; necesidades; democracia; mercado social

\section{The economy of the future must be social and solidary}

ABSTRACT Since the 1980s, worldwide there have been numerous socioeconomic initiatives driven by ideas that differ from capitalist concepts such as accumulation of wealth, maximizing of profits and consumerism. These new initiatives appear all around the economic cycle: resources management, production, marketing, consumption, the financial system, the distribution of surplus and the circulation of currencies. One of the names most commonly associated with such initiatives is social and solidarity economy. In the future these initiatives may provide an alternative to the current dominant system.

KEYWORDS social and solidarity economy; cooperativism; shared; cooperative work; fair trade; responsible consumption; ethical finance; community currencies; solidary distribution of surplus; needs; democracy; social market 


\section{Una economía tan antigua como la humanidad}

El ser humano, como mamífero vulnerable que es, ha tenido que cooperar con sus congéneres para sobrevivir y progresar. La caza, la agricultura o el poblado son fruto de la cooperación humana. Las trazas de la cooperación para resolver necesidades con recursos escasos -la cooperación económica- se encuentran en todas las sociedades precapitalistas: la propiedad comunal y la explotación comunitaria de la tierra de los babilonios, los eslavos o los americanos; las sociedades funerarias y de seguros de los romanos, o los gremios catalanes de lana de la Edad Media que compraban el producto de manera conjunta. Más adelante, en el siglo xIX, ya en plena hegemonía capitalista, la primera clase obrera y el campesinado pobre, para emanciparse, crearon sus cooperativas de consumo, de producción, agrarias y de crédito, además de las mutualidades y los sindicatos y partidos obreros, inspirándose siempre en los valores de libertad, igualdad y fraternidad que las clases populares habían ido extendiendo desde la revolución inglesa de 1640 y que inspiraría después las revoluciones americana y francesa e innombrables revueltas sociales. Con la colonización europea, las formas cooperativa y mutualista se esparcieron por los cinco continentes y conocieron un período de esplendor entre 1880 y 1939.

En los años 1970, la primera gran crisis económica de la posguerra y el auge de los movimientos contestatarios crearon el contexto para que muchos colectivos obreros ocupasen sus fábricas, se hicieran fuertes y las gestionaran por su cuenta mientras el mercado y la policía se lo permitieron, y para que florecieran miles de asociaciones educativas, asistenciales, productivas, culturales, etc., impulsadas por una nueva generación joven con el objetivo de transformar la vida cotidiana aplicando criterios de autogestión e igualdad. Estas iniciativas recibieron el nombre de nueva economía social, para diferenciarla de las cooperativas y las mutualidades tradicionales, que consideraban envejecidas y anquilosadas.

En la década siguiente, la de los años ochenta, las políticas neoliberales aplicadas por las dictaduras militares sobre las poblaciones latinoamericanas provocaron el surgimiento de una economía popular de supervivencia, que en Chile, concretamente en los barrios populares de Santiago en el año 1985, recibió el nombre de economía de la solidaridad o economía solidaria. Mientras tanto, en Europa y América del Norte, grupos de personas solidarias con la gente que sufría la exclusión social por razones diversas, y que la administración tenía abandonadas, promovieron iniciativas sociales para atenderlas, dando lugar a empresas de inserción y fundaciones y asociaciones de intervención social. Al mismo tiempo, algunas plantillas de trabajadores griegos, italianos, catalanes, españoles y portugueses transformaban en cooperativas sus empresas para salvarlas del cierre a causa de la mala gestión o de la reconversión industrial.

Los primeros años del nuevo siglo, estas distintas corrientes coincidieron en los foros sociales mundiales, forjaron una identidad colectiva amparada bajo el nombre de economía social y solidaria (ESS), y se constituyeron en una red intercontinental de promoción de la economía social y solidaria (RIPESS).

La crisis de 2008 propició un notable crecimiento de estas iniciativas y surgieron nuevos tipos, como el procomún y la llamada economía colaborativa. Ambas, la primera claramente y la segunda en su versión no mercantil, se aproximan a la economía social y solidaria.

Podríamos afirmar que, en estos últimos años, la ESS ha conseguido, incluso, cierto reconocimiento institucional, como demuestra su inclusión en las nuevas constituciones venezolana y ecuatoriana, la creación de secretarías ministeriales para promocionarla por parte de los gobiernos brasileño y francés, o en Cataluña las políticas públicas de ESS que empiezan a desplegarse en ayuntamientos vinculados al llamado «nuevo municipalismo».

\section{Una economía completa}

Pero ¿de qué hablamos cuando decimos economía social y solidaria? Pues de una amplísima constelación de prácticas socioeconómicas alternativas a las capitalistas, que abarcan todas las fases del ciclo económico: la gestión de los recursos, la producción, la comercialización, el consumo, el crédito, la distribución del excedente y la circulación monetaria, las cuales comparten unas mismas características. 
En el ámbito de los recursos, estamos pensando en la creación y gestión de bienes comunes. Un común es un bien utilizado por toda la sociedad o por un colectivo determinado de acuerdo con unas reglas de gestión formuladas de modo democrático por esa misma sociedad o colectivo, las cuales permiten que el bien satisfaga con eficacia las necesidades de sus usuarios presentes y también de los futuros. Los comunes se clasifican en dos tipos: los comunes naturales (agua, bosques, zonas de pesca, sistemas de riego, molinos comunitarios...) y los artificiales, que creamos los humanos (las lenguas, la información colaborativa, el software libre...), que también recibe el nombre de procomún. Como ejemplo mencionamos los pastos comunales que todavía existen en algunas partes del Pirineo o del norte peninsular, la Wikipedia, las licencias Creative Commons o los llamados bienes comunes urbanos, como los que se están generando de forma pionera en la ciudad de Bolonia.

En la comercialización, se manifiesta como el comercio justo, entendido como una práctica de intercambio basada en sistemas justos de distribución del trabajo y el excedente de productores, comercializadores y consumidores, unos sistemas que, además, son respetuosos con el medio ambiente. El comercio justo se lleva a cabo mediante los grupos de consumo responsable existentes en muchos barrios o pueblos del país, las tiendas de comercio justo, las agrotiendas de las cooperativas agrarias, las cooperativas de consumo, las ferias campesinas y de economía solidaria, etc.

En el consumo, se plasma en prácticas de consumo responsable realizadas por individuos, entidades, empresas y, últimamente, por algunas administraciones públicas. Por consumo responsable -también llamado crítico, transformador, ético o consciente-, entendemos el consumo de bienes y servicios efectuado de forma consciente con la intención de producir el máximo número de impactos positivos, a la vez que se reducen al mínimo los impactos negativos. El consumo responsable adopta las formas de consumo cooperativo, consumo colaborativo, consumo ecológico, consumo solidario y de reducción voluntaria del consumo.

En el crédito, toma la forma de finanzas éticas, es decir, de entidades y otras herramientas financieras gestionadas democráticamente y que financian proyectos que tienen un impacto social positivo. Estas iniciativas combaten la alineación del ahorrador, producida por su pérdida de control sobre el destino de los ahorros que ingresa en una entidad financiera convencional, y promueven el uso social de la inversión, que es orientada hacia proyectos medioambientales, culturales, de lucha contra la pobreza y la exclusión social, y a favor del desarrollo de la ESS. En Cataluña, cuando hablamos de finanzas éticas nos referimos a Coop57, Fiare, Oikocredit, Acció Solidària contra l'Atur (ASCA) y las comunidades autofinanciadas (CAF), entre otras.

En el reparto del excedente económico, contamos también con experiencias de distribución democrática equitativa y solidaria del excedente. A escala empresarial, nos referimos a las escalas salariales reducidas o incluso inexistentes que se aplican en la mayoría de empresas de la ESS, o al apoyo económico de la empresa hacia actividades sociales y comunitarias. A escala interempresarial, mencionemos los fondos de solidaridad entre empresas, como el existente dentro del grupo cooperativo Mondragón. A escala territorial, lo ilustran los presupuestos municipales participativos practicados por más de doscientos cincuenta ayuntamientos alrededor del mundo.

Florecen también las alternativas al sistema monetario, eso que se conoce por monedas complementarias, sociales o comunitarias. Podríamos definir la moneda comunitaria como una red de intercambio de productos y servicios entre personas y/o empresas, utilizando una moneda (física o virtual) diferente de la oficial, regida por unas normas y unas entidades de naturaleza democrática. Entre las monedas comunitarias, deberíamos diferenciar las monedas locales, es decir, monedas no oficiales utilizadas voluntariamente por los habitantes de una comunidad territorial (por ejemplo, el SOL-Violette en Toulouse, el Bristol Pound en Bristol, el Txantxi en Oñati o La Turuta en Vilanova i la Geltrú), y las monedas sociales, es decir, monedas no oficiales utilizadas voluntariamente por una comunidad profesional o ideológica (por ejemplo, el wir entre las pymes suizas, el sardex entre las empresas de Cerdeña, el puma dentro de la Red de Moneda Social Puma de Sevilla o el boniato en el Mercado Social de Madrid). 


\section{Una economía de productos y servicios}

Hemos dejado para el final del repaso de las iniciativas socioeconómicas alternativas según la fase del ciclo económico en que tienen lugar, la expresión de la ESS en la producción, que podemos llamar producción cooperativa o trabajo cooperativo. La producción constituye probablemente la rama fundamental, la clave de toda la economía; se trata de la creación, a partir de los recursos naturales y del trabajo humano, de productos y servicios útiles para la sociedad.

La producción cooperativa o el trabajo cooperativo es la libre asociación de productores y productoras, que ostentan la propiedad colectiva de la empresa y la gestionan democráticamente bajo el principio de «una persona, un voto».

El trabajo cooperativo se puede llevar a cabo, bien como productor asociado dentro de una cooperativa de trabajo, una sociedad laboral, una asociación o similares, bien como un productor autónomo, pero que colabora con otros dentro de una red de productores o bien dentro de una cooperativa agraria o de servicios.

En estos momentos, existen miles de cooperativas de trabajo y otras empresas de los trabajadores y los productores en todos los sectores de la economía, desde el sector primario hasta los servicios, pasando por la industria. Centrándonos en la forma cooperativa, se estima que hay en el mundo 223 millones de personas que son productores autónomos, sobre todo agricultores, dentro del ámbito de una cooperativa, a las que debemos sumar 26 millones más, que son empleados o socios de cooperativas de trabajo. En algunas regiones del mundo la cooperativización alcanza cifras muy significativas: el 23\% de los puestos de trabajo de la provincia de Ganwon, en Corea del Sur, el 15\% en la región de Emilia-Romaña, en Italia, el 9\% en la provincia de Santa Fe, en Argentina, etc.

Algunas características de la producción cooperativa son la alta seguridad y perdurabilidad de los puestos de trabajo que crea; su capacidad de resiliencia ante las crisis; la mayor presencia y poder de las mujeres (desgraciadamente sin llegar todavía a la paridad); la gestión centrada en las personas; la remuneración similar o superior respecto de otras empresas del mismo sector de actividad, a lo que hay que añadir compensaciones adicionales, sean materiales o no: las escalas salariales más equitativas; la integración laboral de personas desfavorecidas socialmente; la acumulación de reservas financieras más elevada que la media de las empresas, y las innovaciones de producto o servicio para que refleje valores como la sostenibilidad, la participación y la solidaridad.

En cuanto a los retos de la producción cooperativa, cabe mencionar la necesidad de desarrollar más habilidades de gestión y que estén alineadas con los valores y principios de la ESS; el acceso a la financiación; la ausencia de entornos normativos adecuados; la intensificación de la intercooperación empresarial; la profundización en la democracia interna; la participación de los usuarios y clientes, y la acentuación de su compromiso social.

\section{Una economía democrática y responsable}

Constatamos, pues, que la ESS abarca un conjunto de iniciativas socioeconómicas muy heterogéneas. A grandes rasgos, podríamos dividir la ESS en dos subsectores: la ESS socioempresarial (cooperativas, mutualidades, sociedades laborales, asociaciones y fundaciones de carácter social y cultural, empresas de inserción...) y la ESS sociocomunitaria (bancos de tiempo, monedas comunitarias, redes y ferias de intercambio...).

La heterogeneidad del sector se manifiesta en la actividad, la dimensión, el origen, el tipo y la motivación de sus actores, o también en la configuración organizativa que adoptan. Muchas se basan en el trabajo remunerado, algunas en el voluntario, y también están las que los hibridan. Por ahora, la mayoría produce para el mercado capitalista, pero también están las que se orientan hacia la autoproducción, el trueque y el mutualismo. Unas son prácticas esporádicas (por ejemplo, la colaboración desinteresada en un proyecto de software libre para la red), en cambio otras cristalizan en organizaciones informales como las redes de intercambio o las microeconomías comunitarias propias de grupos neorrurales, y muchas otras se configuran como organizaciones formales de carácter empresarial, tipo cooperativa o sociedad laboral, lo que aporta eficacia y continuidad a la actividad, a cambio de arriesgarse a perder frescor y horizontalidad. 
Terminada la descripción, ensayemos una definición. Tenemos dos vías para definir qué es y qué no es la ESS. Una es basarnos en las formas jurídicas, la otra en las prácticas.

La economía social y solidaria catalana está pendiente de que el Parlamento catalán cumpla su compromiso de aprobar una ley de economía solidaria. Hasta ese momento, el marco legal que la acoge es la Ley 5/2011, de 29 de marzo, de economía social, promulgada por las Cortes Generales. Esta norma utiliza el término economía social, pero en buena medida se trata de la misma realidad que otros denominan economía social y solidaria. Pues bien, el artículo 5 de dicha ley establece:

«Forman parte de la economía social las cooperativas, las mutualidades, las fundaciones y las asociaciones que lleven a cabo actividad económica, las sociedades laborales, las empresas de inserción, los centros especiales de trabajo, las cofradías de pescadores, las sociedades agrarias de transformación y las entidades singulares creadas por normas específicas que se rigen por los principios que establece el artículo anterior».

Añadimos que los tipos que integran la economía social y la economía social y solidaria enumerados por esta ley coinciden con los establecidos por las leyes de otros países.

De acuerdo con esto, para decidir si una iniciativa es o no ESS deberemos saber qué fórmula jurídica tiene. Conocer la importancia cuantitativa de la ESS con este criterio también es muy fácil; es suficiente consultar los registros de sociedades. De este modo, por ejemplo, podemos afirmar que en Cataluña existen unas 16.000 entidades de ESS, desglosadas en unas 4.200 cooperativas, 5.000 sociedades laborales, 6.800 asociaciones y fundaciones del campo social, 36 mutualidades de previsión social, 60 empresas de inserción y 210 centros especiales de trabajo. Estas sociedades dan trabajo a casi 190.000 personas, además de otro millón y medio que son socias de consumo o de servicios de estas entidades.

Ahora bien, todos conocemos de primera mano una cooperativa, una sociedad laboral, una fundación o una asociación donde quien trabaja lo hace en pésimas condiciones, que es gestionada de un modo poco democrático y nada participativo, y que no manifiesta ninguna sensibilidad social especial, es decir, que en la práctica funciona como una empresa mercantil privada más.

La constatación de esta realidad nos empuja a intentar acotar la ESS, no desde la voluntad proclamada (la forma jurídica, las declaraciones de misión y valores de la empresa), sino desde la realidad practicada.

Paradójicamente, este otro enfoque encuentra apoyo también en esa misma Ley de economía social, que en su artículo 2 define la economía social como:

«El conjunto de actividades económicas y empresariales que en el ámbito privado llevan a cabo aquellas entidades que, de acuerdo con los principios recogidos en el artículo 4, persiguen, bien el interés colectivo de sus integrantes, bien el interés general económico o social, o los dos a la vez».

Ahora nos preguntaremos: ¿y cuáles son los principios que recoge el artículo 4? Pues:

«a) Primacía de las personas y de la finalidad social sobre el capital, que se concreta en gestión autónoma y transparente, democrática y participativa.

b) Aplicación de los resultados obtenidos de la actividad económica principalmente en función del trabajo aportado y servicio o actividad realizada por los socios o por sus miembros y, si es el caso, a la finalidad social objeto de la entidad.

c) Promoción de la solidaridad interna y con la sociedad.

d) Independencia respecto a los poderes públicos».

Si nos aproximamos a la ESS desde las prácticas, entonces tendremos que descartar todas esas cooperativas, asociaciones, fundaciones, sociedades laborales y otras entidades que, en el día a día, no cumplen con dichos principios. No obstante, por la misma lógica, si lo que importa es la realidad y no la fórmula jurídica, entonces probablemente deberemos considerar que son economía social y solidaria algunas sociedades mercantiles (pequeñas sociedades limitadas, sociedades civiles privadas...) que en la práctica cumplen esos principios, igual que muchos productores autónomos individuales (por ejemplo, una campesina que sigue los principios de la 
agroecología y vende a los grupos de consumo responsables), y también añadir un montón de prácticas económicas comunitarias que igualmente los cumplen, como son los bancos de tiempo, las monedas comunitarias, las redes y ferias de intercambio o los grupos de crianza compartida, aunque no tengan una cobertura legal. ¿Por qué razón, sino, las deberíamos excluir?

De modo que de utilizar una aproximación u otra, resulta un perímetro parcialmente distinto. En mi opinión, lo más útil es definir la ESS sobre todo desde las prácticas, pero concediendo un tipo de moratoria para que aquellas iniciativas de ESS que hoy «suspenderían» si alguien evaluara su actuación tengan tiempo para mejorar y para que el uso de instrumentos que sirvan para medir la aplicación de principios de la ESS (el balance social, el mapa colaborativo de Cataluña denominado Pam a Pam, etc.) se generalicen.

Desde las prácticas, podemos ensayar una definición sintética de la economía social y solidaria: el conjunto de iniciativas socioeconómicas de todo tipo, formales o informales, individuales o colectivas, que prioricen la satisfacción de las necesidades de sus miembros y/o de otras personas por encima del lucro; que sean de propiedad colectiva, naturalmente cuando son colectivas, y no iniciativas individuales; que se gestionen de forma democrática; que sean independientes respecto a los poderes públicos, y actúen orientadas por valores como la equidad, la solidaridad, la sostenibilidad, la participación, la inclusión y el compromiso con la comunidad.

Aclaremos un par de aspectos de esta definición. Nos referimos a iniciativas, como podríamos hablar de prácticas, pero no de entidades, ya que restringiría la ESS a sus manifestaciones formalizadas y estables, cuando, en cambio, consideramos que cualquier persona, física o jurídica -un individuo, cualquier tipo de empresa o asociación, una administración-, puede realizar acciones de ESS; por ejemplo, de consumo responsable, que pueden practicar todos los individuos y organizaciones incluida la administración pública (compra pública responsable).

Segunda aclaración: estas iniciativas las caracterizamos de "socioeconómicas», porque consideramos que economía y sociedad deberían estar siempre entrelazadas y que, obviamente, la economía que denominamos «social y solidaria» lo está.

\section{Una economía de presente y de futuro}

La ESS constituye un fenómeno extendido alrededor del mundo, minoritario pero de ningún modo insignificante. Sus iniciativas mejoran las condiciones de vida de la población, proporcionan alimentos a bajo precio, generan puestos de trabajo de calidad, aumentan las rentas agrarias y preservan el mundo rural, otorgan créditos a los sectores populares, facilitan viviendas asequibles, permiten que pequeñas tiendas sobrevivan a la competencia de las grandes cadenas comerciales, fortalece la economía local, etc. Además, fomentan los valores democráticos, solidarios, proactivos y críticos de las personas, que devienen ciudadanos activos y sujetos transformadores. Pero eso no es todo.

Hoy en día, la ESS constituye en la práctica un gran y variado laboratorio de innovación social que ensaya nuevas formas de trabajar, gestionar, consumir y financiarse, y un escaparate que muestra a los ojos de todo el mundo que quiera ver que es posible hacer economía de una manera eficaz y, a la vez, democrática, solidaria, justa y sostenible. Por eso no nos tiene que sorprender tampoco que muchos investigadores sociales (entre ellos los economistas) busquen en la ESS una fuente de inspiración. Desde la crisis de 2008, la ESS inspira tanto a los que aspiran a civilizar el capitalismo como a los que buscan modelos económicos alternativos.

Así mismo, la ESS solo puede convertirse en una parte de una alternativa al capitalismo si gana densidad, dimensión y complejidad, y pasa de la escala micro (las iniciativas y empresas individuales) a la escala meso (los ecosistemas territoriales y sectoriales de iniciativas de ESS). Para eso necesita crecer y vertebrarse; profundizar en un modelo de gestión basado en los valores alternativos que representa y no en el management capitalista; penetrar en mercados de importancia estratégica, como los vinculados a la economía verde; orientarse hacia el desarrollo autocentrado del sector, o en otras palabras, hacia la creación de mercados sociales alternativos; presionar para que las políticas públicas le sean favorables, lo que exige que sean coproducidas entre la administración y el propio sector, y tomar conciencia de sí mismo, profundizando en su identidad y erigiéndose en un actor 
económico y político influyente, aliado con otros movimientos sociales transformadores y con otras economías críticas como la feminista y la ecologista.

\section{Conclusiones}

La economía social y solidaria está resolviendo las necesidades de millones de personas en el mundo y lo hace tanto democratizando la sociedad como inspirando nuevos sistemas económicos más justos y sostenibles. La gran fortaleza de la ESS es que no se trata de ninguna elucubración teórica, tampoco de ningún ideal abstracto, sino de una realidad palpable. No obstante, todavía debe desarrollarse mucho y superar difíciles retos para convertirse en una alternativa real a la economía capitalista.

\section{Referencias bibliográficas}

CONILL, J. y otros (2012). Otra vida es posible. Barcelona: UOC.

CORAGGIO, J. L. (2004). La gente o el capital. Buenos Aires: Espacio Editorial.

CORAGGIO, J. L. y otros (2013). Diccionario de la otra economía. Buenos Aires: Universidad Nacional de General Sarmiento.

DIVERSOS AUTORES (2010). «Economía solidaria, potencialidades y desafíos». Revista Papeles. N. ${ }^{0} 110$. Barcelona: Icaria.

GARCIA, J. y otros (2001). La dimensió cooperativa. Barcelona: Icaria.

GARCIA, J.; LAVILLE, J. L. (2009). Crisis capitalista y economía solidaria. Barcelona: Icaria.

GUERRA, P. A. (2002). Socioeconomía de la solidaridad. Montevideo: Nordan.

LAVAL, C.; DARDOT, P. (2015). Común. Barcelona: Gedisa.

LAVILLE, J. L. (2004). Economía social y solidaria, una visión europea. Buenos Aires: Fundación OSDE. 


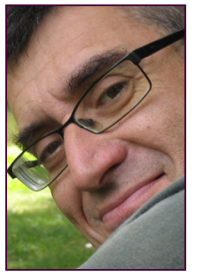

\section{Jordi Garcia Jané} jordi@apostrof.coop

\section{Socio de la cooperativa L'Apòstrof}

Docente, escritor y conferenciante habitual sobre temas de cooperativismo, economía social y solidaria, democracia participativa, innovación social, y alternativas sociales en general. Además de numerosos artículos para revistas como lllacrua, Actualitat i Alternatives, Cooperatives de Treball, Cooperació Catalana, Nexe Quaderns d'Autogestió Cooperativa o el semanario Directa, es autor o coautor de libros como La dimensió cooperativa (2001, 2006), Economía solidaria y crisis capitalista (2010), Democracia económica (2011), Adéu capitalisme. 15M-2031 (2012) y Economia solidària per a una Catalunya lliure (2014).

Trabaja en la cooperativa L'Apòstrof y participa activamente en otras cooperativas y entidades de economía social y solidaria, como la Xarxa d’Economia Solidària (XES).

Los textos publicados en esta revista están sujetas -salvo que se indique el contrario- a una licencia de Reconocimiento 3.0 España de Creative Commons. Podéis copiarlos, distribuirlos, comunicarlos públicamente y hacer obras derivadas siempre que reconozcáis los créditos de las obras (autoría, nombre de la revista, institución editora) de la manera especificada por los autores o por la revista. La licencia completa se puede consultar en http://creativecommons.org/licenses/by/3.0/es/deed.ca.

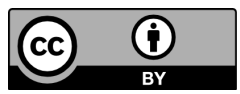

